\title{
Intracranial pressure elevations in diffuse axonal injury: association with nonhemorrhagic MR lesions in central mesencephalic structures
}

\author{
Sami Abu Hamdeh, MD, ${ }^{1}$ Niklas Marklund, MD, PhD, ${ }^{1}$ Anders Lewén, MD, PhD, ${ }^{1}$ Tim Howells, PhD, ${ }^{1}$ \\ Raili Raininko, MD, PhD, ${ }^{2}$ Johan Wikström, MD, PhD, ${ }^{2}$ and Per Enblad, MD, PhD1 \\ 1Department of Neuroscience/Neurosurgery, Uppsala University; and 'Department of Surgical Sciences/Radiology, Uppsala \\ University, Uppsala, Sweden
}

\begin{abstract}
OBJECTIVE Increased intracranial pressure (ICP) in patients with severe traumatic brain injury (TBI) with diffuse axonal injury (DAI) is not well defined. This study investigated the occurrence of increased ICP and whether clinical factors and lesion localization on MRI were associated with increased ICP in patients with DAI.
\end{abstract}

METHODS Fifty-two patients with severe TBI (median age 24 years, range 9-61 years), who had undergone ICP monitoring and had DAI on MRI, as determined using T2*-weighted gradient echo, susceptibility-weighted imaging, and diffusion-weighted imaging (DWI) sequences, were enrolled. The proportion of good monitoring time (GMT) with ICP $>20 \mathrm{~mm} \mathrm{Hg}$ during the first 120 hours postinjury was calculated and associations with clinical and MRI-related factors were evaluated using linear regression.

RESULTS All patients had episodes of ICP $>20 \mathrm{~mm} \mathrm{Hg}$. The mean proportion of GMT with ICP > $20 \mathrm{~mm} \mathrm{Hg}$ was $5 \%$, and $27 \%$ of the patients (14/52) spent more than $5 \%$ of GMT with ICP $>20 \mathrm{~mm} \mathrm{Hg}$. The Glasgow Coma Scale motor score at admission $(p=0.04)$ and lesions on DWI sequences in the substantia nigra and mesencephalic tegmentum (SN-T, $p=0.001$ ) were associated with the proportion of GMT with ICP $>20 \mathrm{~mm} \mathrm{Hg}$. In multivariable linear regression, lesions on DWI sequences in SN-T ( $8 \%$ of GMT with ICP > $20 \mathrm{~mm} \mathrm{Hg}, 95 \% \mathrm{Cl} 3 \%-13 \%, p=0.004$ ) and young age $(-0.2 \%$ of GMT with ICP $>20 \mathrm{~mm} \mathrm{Hg}, 95 \% \mathrm{Cl}-0.07 \%$ to $-0.3 \%, p=0.002)$ were associated with increased ICP.

CONCLUSIONS Increased ICP occurs in approximately one-third of patients with severe TBI who have DAI. Age and lesions on DWI sequences in the central mesencephalon (i.e., SN-T) are associated with elevated ICP. These findings suggest that MR lesion localization may aid prediction of increased ICP in patients with DAI.

https://thejns.org/doi/abs/10.3171/2018.4.JNS18185

KEYWORDS diffuse axonal injury; MRI; elevated ICP; intracranial pressure; TBI; traumatic brain injury; diffusion-weighted imaging; trauma

$\mathrm{T}$ Raumatic brain injury (TBI) is the most frequent cause of death and disability among young and middle-aged adults. ${ }^{22,30} \mathrm{TBI}$ is a markedly heterogeneous disease, and commonly it is classified based on biomechanical and radiological features into focal or diffuse injuries. Diffuse axonal injury (DAI), biomechanically linked to rotational acceleration-deceleration injury to the brain, leads to widespread axonal injury in superficial and deep white matter structures. ${ }^{2}$ This injury type causes damage to white matter axons with resulting disruption of neuronal networks and emotional, cognitive, and behavioral symptoms. ${ }^{5,6,10,13,19}$ In its severe form it is characterized by prolonged coma and poor prognosis. ${ }^{1,3,17}$

Available prognostic methods in DAI are unreliable and the clinical characteristics are highly variable, making DAI a challenging clinical entity. Typically in more severe cases, the patients are deeply unconscious with minimal lesions visualized on the initial CT scans, because this im-

ABBREVIATIONS ADC = apparent diffusion coefficient; $\mathrm{CPP}=$ cerebral perfusion pressure; $\mathrm{DAI}$ = diffuse axonal injury; $\mathrm{DWI}=$ diffusion-weighted imaging; $\mathrm{EVD}=$ external ventricular drain; GCS = Glasgow Coma Scale; GMT = good monitoring time; GOSE = Glasgow Outcome Scale-Extended; ICC = intraclass correlation coefficient; ICP = intracranial pressure; MAP = mean arterial blood pressure; NICU = neurointensive care unit; SN-T = substantia nigra and mesencephalic tegmentum; SWI = susceptibilityweighted imaging; $\mathrm{TBI}=$ traumatic brain injury; $\mathrm{T} 2^{*} \mathrm{GRE}=\mathrm{T} 2^{*}$-weighted gradient echo .

SUBMITTED January 21, 2018. ACCEPTED April 5, 2018.

INCLUDE WHEN CITING Published online September 14, 2018; DOI: 10.3171/2018.4.JNS18185. 
aging modality is insensitive to subtle axonal damage. ${ }^{11}$ MRI with sequences sensitive to hemorrhagic lesions and/ or cytotoxic edema can visualize DAI by detecting even microscopic amounts of blood or nonhemorrhagic lesions secondary to axonal strain in deep white matter structures. Nonetheless, to predict which patient with DAI eventually regains consciousness and attains a favorable outcome is still difficult. ${ }^{3,4,16}$ In addition, it is also difficult to predict the risk of developing high intracranial pressure (ICP), and studies evaluating the prevalence of increased ICP in DAI provide contradictory results. ${ }^{21,28,29,39}$ Thus, the risk of secondary injury development due to ICP elevations is not well defined.

Recently we have identified central brainstem lesions in the region of the substantia nigra and mesencephalic tegmentum (SN-T) as particularly and independently associated with poor outcome. ${ }^{1}$ Based on these findings, a classification system was proposed, extending the established grading system of Adams et al., ${ }^{2}$ with the SN-T lesions as an essential component, to improve outcome prediction. In this study, the aims were to investigate the occurrence of increased ICP in patients with DAI and to analyze whether the classification system or any of its integral parts also were associated with the development of elevated ICP in patients with DAI.

\section{Methods}

The Regional Research Ethics Committee granted permission for all included studies. Written informed consent was obtained from the closest relative of the patient with TBI, and all research was conducted in accordance with the ethical standards given in the Helsinki Declaration of 1975, as revised in 2008.

\section{Patients and Neurointensive Care}

Patients were admitted to the neurointensive care unit (NICU) at the Uppsala University Hospital (a level I trauma center) for severe TBI (defined as a postresuscitation Glasgow Coma Scale [GCS] score $\leq 8$ ) between 2007 and 2015. They were in need of insertion of an ICP monitoring device. They had no mass lesions larger than $25 \mathrm{~cm}^{3}$, nor did they have ischemic/vascular lesions. Patients with DAI-associated lesions confirmed on MRI were eligible for the study.

Patients were treated at the NICU using a standardized treatment protocol, which included mechanical ventilation and sedation/analgesia provided using a combination of intermittent intravenous morphine analgesia (1-3 mg of Morfin Meda; Meda) and continuous intravenous propofol infusion (1-4 mg/kg/hr Propofol-Lipuro; B. Braun Melsungen AG) in unconscious patients (GCS motor score $1-5)$. In those patients, an ICP monitoring device was inserted for continuous measurements of ICP and cerebral perfusion pressure (CPP). The protocol was ICP- and CPP-guided and included mild hyperventilation initially $\left(\mathrm{PaCO}_{2} 30-35 \mathrm{~mm} \mathrm{Hg} ; 4.0-4.5 \mathrm{kPa}\right), 30^{\circ}$ elevated head of bed, volume expansion to normovolemia, and a central venous pressure of $0-5 \mathrm{~mm} \mathrm{Hg}$. ${ }^{9}$ The aim of treatment was to keep ICP $<20 \mathrm{~mm} \mathrm{Hg}$ and CPP $>60 \mathrm{~mm} \mathrm{Hg}$ according to an organized secondary insult program. Elevated
ICP that was not controlled by standard therapy or CSF drainage was treated with pharmacologically induced coma. Continuous propofol infusions without neurological wake-up tests ${ }^{32}$ were used initially and continuous sodium pentobarbital infusion therapy and/or a decompressive craniectomy as second-tier therapy.

\section{Imaging and Image Analysis}

An initial CT scan was performed on admission and scored according to the Marshall classification. ${ }^{25}$ Suspected DAI on the initial CT was subsequently confirmed with MRI when the patient was medically stable and it was possible to transfer them to the radiology department. MRI was performed with a 1.5-T scanner (Siemens Avanto; Siemens Healthineers). Imaging included a T2*-weighted gradient echo (T2*GRE) sequence (TR $500 \mathrm{msec}$, TE 14 msec, flip angle $30^{\circ}$, acquisition voxel $0.9 \times 0.9 \times 3 \mathrm{~mm}$ ); a diffusion-weighted imaging (DWI) sequence (SE-EPI, bvalue $1000 \mathrm{sec} / \mathrm{mm}^{2}$, TR $4700 \mathrm{msec}$, TE $89 \mathrm{msec}$, acquisition voxel $1.2 \times 1.2 \times 5 \mathrm{~mm}$ ); and a susceptibility-weighted imaging (SWI) sequence (TR $49 \mathrm{msec}$, TE $40 \mathrm{msec}$, flip angle $15^{\circ}$, acquisition voxel $0.9 \times 0.9 \times 1.5 \mathrm{~mm}$ ). Hemorrhagic lesions were assessed on T2*GRE and/or SWI sequences depending on availability.

Two of the authors (S.A.H. and J.W.) assessed the images independently for anatomical lesion localization, DAI grading, and DAI staging as described in detail previously. ${ }^{1}$ Briefly, DAI-associated lesions were defined as hypointense or decreased signals on T2*GRE and SWI sequences, and/or high signal intensity on DWI sequences in white matter structures not extending to the cortex. The number of DAI-associated lesions was counted on each side of the midline in different anatomical locations of the brain. Adams' anatomical histopathological grading system was applied (grade I, lesions in cerebral hemispheres only; grade II, lesions in corpus callosum; and grade III, brainstem lesions) ${ }^{2}$ for each sequence separately. In addition, DAI staging, according to previously published work by our group, was performed using all sequences combined (stage I, lesions in cerebral hemispheres only; stage II, lesions in corpus callosum; stage III, lesions in the brainstem excluding the SN-T; and stage IV, lesions in SN-T). ${ }^{1}$ Both raters were blinded to patient outcome.

The interrater agreement was calculated for agreement of DAI staging between the 2 evaluators and for the total number of DAI-associated lesions for all 3 sequences. The interrater agreement was analyzed using linear weighted Cohen's $\mathrm{K}$ statistics for categorical values, and the intraclass correlation coefficient (ICC) was calculated with 2-way random single measures (consistency/absolute agreement) for continuous values. Values of $\leq 0.2$ were considered poor, $0.21-0.4$ fair, $0.41-0.6$ moderate, $0.61-0.8$ good, and $\geq 0.81$ very good agreement for both $\kappa$ and ICC values. Disagreement was settled with a mutual evaluation of images by S.A.H. and J.W., and the agreed consensus was used for data analysis.

\section{Physiological Data Collection}

Physiological data were collected using a computerized multimodality monitoring system providing minute-by- 
minute average values. ${ }^{15}$ Manual assessments of data were performed to withdraw invalid data from the total monitoring time. Interruption of physiological data collection occurred when the patient was taken to surgery or radiology and during network or software failures. The remaining monitoring data, the good monitoring time (GMT), was assessed for ICP, CPP, and mean arterial blood pressure (MAP). The GMT for the first 120 hours after initiation of monitoring was used for analysis, and a minimum of 24 hours of GMT was required for inclusion. Treatment goals for ICP, CPP, and MAP included ICP $<20 \mathrm{~mm} \mathrm{Hg}$, CPP $>60 \mathrm{~mm} \mathrm{Hg}$, and MAP > $70 \mathrm{~mm} \mathrm{Hg}$. The proportions of GMT above or below the treatment goal for each parameter were calculated and are presented as percent of GMT.

\section{Outcome}

Using the Glasgow Outcome Scale-Extended (GOSE), we assessed outcome at $\geq 6$ months (median 7, range 6-25 months) after the injury. Patients were assessed by an intensive care specialist nurse, who was trained to perform the structured interview and blinded to all clinical data. A standardized questionnaire was used, based on the structured interviews by Wilson et al., ${ }^{38}$ to be filled out by patients or their closest relative. When supplementary information was needed, patients or relatives were contacted by telephone.

\section{Statistical Methods}

Statistica 13.0 (Stat Soft, Inc.) was used for descriptive and analytical statistics. Univariate linear regression was used to analyze the association between the proportion of GMT with ICP $>20 \mathrm{~mm} \mathrm{Hg}$ during the first 120 hours and clinical and MRI-related variables. The significance level was defined as $\mathrm{p}=0.05$.

Potential predictors of increased ICP with significant or near-significant association with the proportion of GMT with ICP > $20 \mathrm{~mm} \mathrm{Hg}$ were further analyzed in a multivariable linear regression model to evaluate independent associations of each variable. In addition, age and the Marshall CT score, two factors known to influence ICP, 8,25 were included in the analysis.

\section{Results \\ Clinical Results}

Fifty-two patients were included in the study. Demographic and clinical characteristics of the patient cohort are provided in Table 1. For ICP monitoring, an intraparenchymal ICP monitoring device (Codman ICP express; Codman Neuro) was used in 32 patients, an external ventricular drain (EVD; Smith Medical) in 16, and a combination of both were used in 4 patients. The mean GMT for ICP was 102 hours ( \pm 19 hours SD) during the first 120 hours from the start of monitoring. Proportions of GMT with ICP $>20 \mathrm{~mm} \mathrm{Hg}$ are provided in Fig. 1A. Episodes of ICP $>20 \mathrm{~mm} \mathrm{Hg}$ were present in all patients, and $27 \%$ of patients (14/52) spent more than 5\% of GMT with ICP $>20 \mathrm{~mm} \mathrm{Hg}$. The mean proportion of GMT with ICP > $20 \mathrm{~mm} \mathrm{Hg}$ was $5 \%$ of monitoring time $( \pm 7 \%$ SD). Thirtyfour patients $(65.4 \%)$ were managed by using basal ICP treatment only, whereas the remaining 18 patients (34.6\%)
TABLE 1. Demographic and clinical characteristics of the $\mathbf{5 2}$ patients in the cohort

\begin{tabular}{|c|c|}
\hline Variable & Value $(\%)$ \\
\hline Median age (yrs) & 24 , range $9-61$ \\
\hline $\operatorname{Sex}(M / F)$ & $40 / 12(77 / 23)$ \\
\hline Median length of NICU stay (days) & 13 , range $4-69$ \\
\hline \multicolumn{2}{|l|}{ Injury mechanism } \\
\hline MVA & $34(65.4)$ \\
\hline Sports & $10(19.2)$ \\
\hline Fall & $5(9.6)$ \\
\hline Assault & $2(3.8)$ \\
\hline $\mathrm{HBO}$ & $1(1.9)$ \\
\hline Median admission GCS motor score & 5 , range $6-1$ \\
\hline \multicolumn{2}{|l|}{ Motor deficit } \\
\hline None & $28(53.8)$ \\
\hline Extremity & $9(17.3)$ \\
\hline Hemiparesis & $12(23.1)$ \\
\hline Tetraparesis & $3(5.8)$ \\
\hline Extracranial injury & $37(71.1)$ \\
\hline Mean ISS & 25.6 , range $16-50$ \\
\hline \multicolumn{2}{|l|}{ Marshall score } \\
\hline Diffuse injury I & $2(3.8)$ \\
\hline Diffuse injury II & $39(75)$ \\
\hline Diffuse injury III & $11(21.1)$ \\
\hline \multicolumn{2}{|l|}{ ICP management } \\
\hline Basal treatment & $34(65.4)$ \\
\hline CSF drainage & $9(17.3)$ \\
\hline Propofol coma & $7(13.5)$ \\
\hline Barbiturate coma & $2(3.8)$ \\
\hline Median GCS motor score at discharge & 6 , range $6-1$ \\
\hline \multicolumn{2}{|l|}{ GOSE score at $\geq 6$ mos } \\
\hline $1-2$ & $4(7.7)$ \\
\hline $3-4$ & $15(28.8)$ \\
\hline $5-6$ & $12(23.1)$ \\
\hline $7-8$ & $16(30.8)$ \\
\hline LTF & $5(9.6)$ \\
\hline
\end{tabular}

HBO = hit by object; ISS = Injury Severity Score; LTF = lost to follow-up; MVA $=$ motor vehicle accident.

needed escalation of the ICP management. Of these, 9 patients (17.3\%) required drainage of CSF via an EVD, 7 patients (13.5\%) were treated with propofol coma, and 2 patients $(3.8 \%)$ required addition of barbiturate coma to manage increased ICP. No patient required a decompressive craniectomy.

\section{Imaging Results}

The Marshall CT score on admission was diffuse injury I in 2 patients (3.8\%), diffuse injury II in 39 patients (75\%), and diffuse injury III in 11 patients (21.1\%).

MRI was performed at a mean of 7 days (range 1-37 days; MRI 1st week [n = 37], MRI 2nd week [ $\mathrm{n}=10]$, MRI late $[\mathrm{n}=5]$ ) postinjury. The DWI sequence was not 

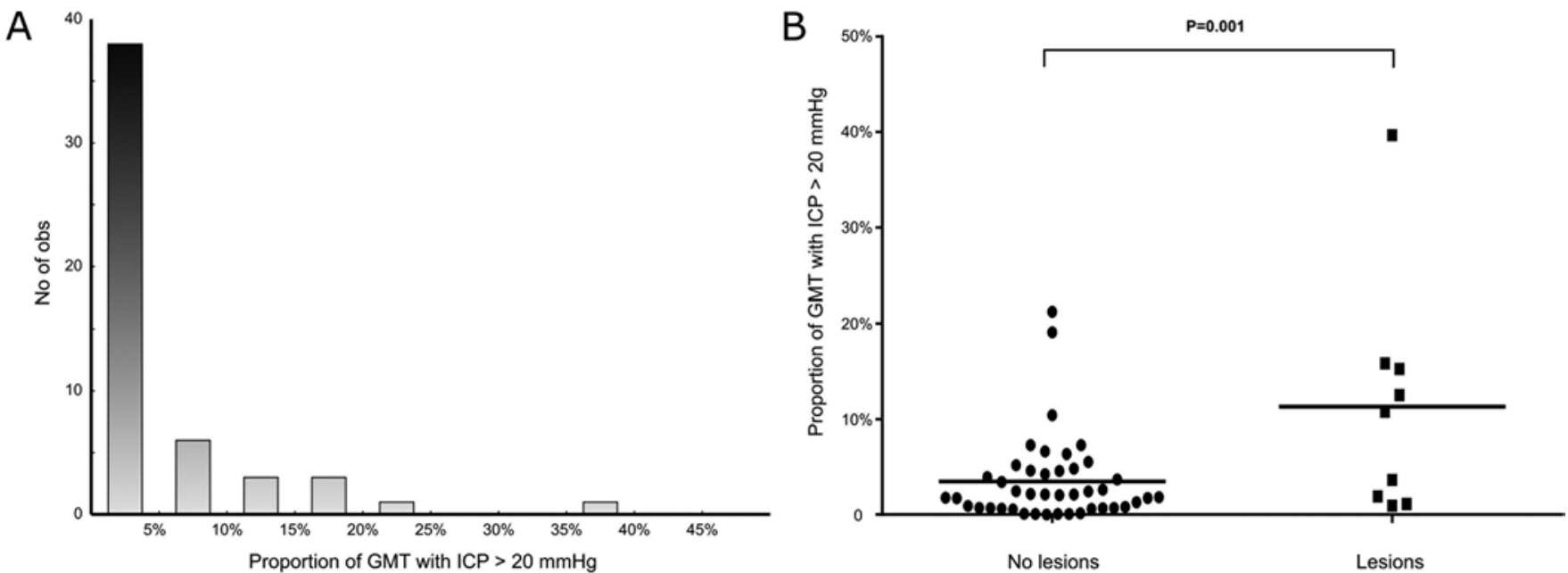

FIG. 1. A: Bar graph displaying the distribution of ICP $>20 \mathrm{~mm} \mathrm{Hg}$ in the patient cohort. The number of patients by the proportion of GMT with ICP > $20 \mathrm{~mm} \mathrm{Hg}$ is depicted. B: Dot plot displaying individual and mean proportion of GMT > $20 \mathrm{~mm}$ Hg in patients with (lesions) and without (no lesions) DWI-confirmed lesions in the SN-T. DWI lesions in the SN-T were significantly associated with the proportion of GMT with ICP $>20 \mathrm{~mm} \mathrm{Hg}(p=0.001$ in univariate linear regression, $p=0.004$ in multivariable linear regression). Obs = observations.

available in 1 patient (1.9\%), and both $\mathrm{T} 2 * \mathrm{GRE}$ and SWI sequences were unavailable in 2 patients (3.8\%). The Adams' DAI grade ${ }^{2}$ on the DWI sequences was grade I in 5 patients $(9.6 \%)$, grade II in 23 patients $(44.2 \%)$, and grade III in 22 patients $(42.3 \%)$, whereas 1 patient $(1.9 \%)$ had no pathology on DWI sequences. The DAI grade on the $\mathrm{T} 2 * \mathrm{GRE}$ or the SWI sequences was grade I in 6 patients $(11.5 \%)$, grade II in 14 patients $(26.9 \%)$, and grade III in the remaining 30 patients $(57.7 \%)$. The DAI stage according to the MRI classification previously reported by our group $^{1}$ using all sequences was stage I in 2 patients (3.8\%), stage II in 16 patients (30.8\%), stage III in 11 patients (21.2\%), and stage IV in 23 patients (44.2\%).

The ICC showed good agreement between raters for quantification of the total lesion load of DAI-associated lesions for all sequences (ICC $=0.68$ for T2*GRE, ICC $=0.67$ for DWI, and ICC $=0.78$ for SWI sequences). The Cohen's $\kappa$ showed very good agreement between raters for DAI staging (Cohen's $\kappa=0.87$ ).

\section{Association With Intracranial Hypertension}

The univariate analysis (Table 2) of clinical factors including Marshall CT score showed that the GCS motor score on admission had a statistically significant association to the proportion of GMT with ICP $>20 \mathrm{~mm} \mathrm{Hg}$ (p $=0.04)$. Near-significant association was found for sex $(\mathrm{p}$ $=0.07)$ and motor deficit at admission $(p=0.06)$. The remaining clinical factors did not show any significant association to the proportion of GMT with ICP $>20 \mathrm{~mm} \mathrm{Hg}$.

The univariate analysis of MRI variables showed that lesions in the SN-T region were associated with the proportion of GMT with ICP $>20 \mathrm{~mm} \mathrm{Hg}$ for the DWI sequences $(p=0.001$; Table 2, Fig. $1 B)$, whereas lesions in the tectum $(\mathrm{p}=0.81)$ and the total number of lesions in the brainstem $(\mathrm{p}=0.06)$ were not. On the T2*GRE and SWI sequences, there were no associations between the lesions in the brainstem and increased ICP ( $p=0.83$ for SN-T, $p$
$=0.34$ for tectum, and $\mathrm{p}=0.99$ for the total number of lesions). The total lesion load of DAI-associated lesions was not associated with increased ICP either in the DWI sequences $(\mathrm{p}=0.27)$ or in the T2*GRE and SWI sequences $(p=0.75)$. The proportion of GMT with ICP $>20 \mathrm{~mm}$ $\mathrm{Hg}$ was associated with neither the DAI grade $(\mathrm{p}=0.26$ for $\mathrm{T} 2 * \mathrm{GRE}$ and SWI sequences and $\mathrm{p}=0.09$ for DWI sequences) nor the DAI stage ( $\mathrm{p}=0.41)$.

In the multivariable linear regression analysis (Table 3 ), lesions in the SN-T on the DWI sequences (8\% of GMT with ICP > $20 \mathrm{~mm} \mathrm{Hg}, 95 \%$ CI $3 \%-13 \%, \mathrm{p}=0.004)$ and younger age $(-0.2 \%$ of GMT with ICP $>20 \mathrm{~mm} \mathrm{Hg}, 95 \%$ CI $-0.07 \%$ to $-0.3 \%, \mathrm{p}=0.002$ ) were independently associated with the proportion of GMT with ICP $>20 \mathrm{~mm} \mathrm{Hg}$.

\section{Clinical Outcome}

After $\geq 6$ months, 16 patients $(30.8 \%)$ had a good recovery (GOSE 7-8), 12 patients (23.1\%) were moderately disabled (GOSE 5-6), 15 patients $(28.8 \%)$ were severely disabled (GOSE 3-4), and 4 patients (7.7\%) were either in a vegetative state or dead (GOSE 1-2). The proportion of GMT with ICP $>20 \mathrm{~mm} \mathrm{Hg}$ was associated with the unfavorable outcome measured by GOSE at $\geq 6$ months postinjury $(\mathrm{p}=0.05)$.

\section{Discussion}

This study investigated the occurrence of increased ICP in patients with DAI and whether clinical factors and lesion localization on MRI were associated with ICP elevations. It was found that elevations of ICP were not uncommon among the patients with DAI and that escalated treatment was needed in approximately one-third of the patients. Younger age and lesions in the central brainstem-i.e., in the region of the SN-T- on DWI sequences were associated with the proportion of monitoring time with increased ICP. 
TABLE 2. Univariate linear regression with the proportion of GMT with ICP > $20 \mathrm{~mm} \mathrm{Hg}$ during the first 120 hours as the dependent variable

\begin{tabular}{|c|c|c|}
\hline Variable & $\begin{array}{l}\text { Regression Coefficient } \\
\qquad(95 \% \mathrm{Cl})\end{array}$ & $\begin{array}{c}p \\
\text { Value }\end{array}$ \\
\hline Age (yrs) & NS & 0.22 \\
\hline $\operatorname{Sex}(M / F)$ & NS & 0.07 \\
\hline ISS & NS & 0.27 \\
\hline Injury mechanism & NS & 0.89 \\
\hline Length of stay & NS & 0.36 \\
\hline Marshall score & NS & 0.16 \\
\hline MLS (yes/no) & NS & 0.86 \\
\hline Admission GCS motor score* & $7 \%(4-11 \%)$ & 0.04 \\
\hline Motor deficit (yes/no) & NS & 0.06 \\
\hline Extracranial injury & NS & 0.17 \\
\hline DAl grade on T2*GRE/SWI† & NS & 0.26 \\
\hline DAl grade on DWI & NS & 0.09 \\
\hline DAl stage (all sequences) $\ddagger$ & NS & 0.41 \\
\hline SN-T SWI & NS & 0.83 \\
\hline Tectum SWI & NS & 0.34 \\
\hline Brainstem SWI & NS & 0.99 \\
\hline SN-T DWI & $7 \%(3-11 \%)$ & 0.001 \\
\hline Tectum DWI & NS & 0.81 \\
\hline Brainstem DWI & NS & 0.06 \\
\hline Total brain lesion load SWI & NS & 0.75 \\
\hline Total brain lesion load DWI & NS & 0.27 \\
\hline
\end{tabular}

MLS = midline shift; NS = not significant.

The significance level was defined as 0.05 . The regression coefficient is expressed as the increase (positive value) or decrease (negative value) of percent of GMT with ICP $>20 \mathrm{~mm} \mathrm{Hg}$ for every unit increase of the predictive variable. Boldface type indicates statistical significance.

* Presented as regression coefficient for GCS motor score 1 (no motor response).

† Grading according to Adams et al. (grade I, lesions in cerebral hemispheres only; grade II, lesions in corpus callosum; and grade III, brainstem lesions). $\ddagger$ Staging according to Abu Hamdeh et al. (stage I, lesions in cerebral hemispheres only; stage II, lesions in corpus callosum; stage III, lesions in the brainstem excluding the SN-T; and stage IV, lesions in the SN-T).

Elevated ICP is considered to be deleterious in TBI..$^{24,28,}$ ${ }^{34,37}$ However, the prevalence of elevated ICP in DAI is not well defined. In an early analysis of the experience of ICP monitoring of 207 patients with severe head injury, Narayan et al. reported that patients with normal findings on initial CT examination generally do not have elevated ICP. ${ }^{28}$ On the contrary, in another study, elevated ICP was observed despite the absence of mass lesions, midline shift, or compressed basal cisterns on the initial CT scan in seveneighths of the cases. ${ }^{29}$ In a later publication ${ }^{21}$ including 36 patients with pure DAI that had been diagnosed with clinical and CT-related criteria, the patients with DAI were not found to have elevated ICP to the same extent as patients suffering other types of severe TBI. The authors concluded that it could be possible to refrain from ICP monitoring in this group, avoiding the complication risk of EVD placement. Noteworthy, however, was the observation of periods of ICP > $20 \mathrm{~mm} \mathrm{Hg}$ in $10 \%$ of patients. This observation is
TABLE 3. Multivariable linear regression with significant or nearsignificant univariate variables

\begin{tabular}{lcc}
\hline \multicolumn{1}{c}{ Variable } & $\begin{array}{c}\text { Regression Coefficient } \\
(95 \% \mathrm{Cl})\end{array}$ & $\begin{array}{c}\mathrm{p} \\
\text { Value }\end{array}$ \\
\hline SN-T DWI lesions & $8 \%(3-13 \%)$ & $\mathbf{0 . 0 0 4}$ \\
\hline Age & $-0.2 \%(-0.07 \%$ to $-0.3 \%)$ & $\mathbf{0 . 0 0 2}$ \\
\hline Marshall score & $\mathrm{NS}$ & 0.06 \\
\hline Brainstem DWI & $\mathrm{NS}$ & 0.80 \\
\hline Sex & $\mathrm{NS}$ & 0.43 \\
\hline Admission GCS motor score & NS & 0.79 \\
\hline Motor deficit (yes/no) & NS & 0.52 \\
\hline
\end{tabular}

In addition to the significant and near-significant univariate variables, age and Marshall score were included in the model. The significance level was defined as 0.05 . The regression coefficient is expressed as the increase (positive value) or decrease (negative value) of percent of GMT with ICP $>20 \mathrm{~mm}$ $\mathrm{Hg}$ for every unit increase of the predictive variable. Boldface type indicates statistical significance.

in accordance with the results of the present study, showing that a significant number of patients with DAI had ICP > $20 \mathrm{~mm} \mathrm{Hg}$ during a substantial proportion of time despite escalated treatment focused on avoiding ICP insults.

In our study, episodes of ICP $>20 \mathrm{~mm} \mathrm{Hg}$ were evident in all patients, and $27 \%$ had increased ICP for more than $5 \%$ of the monitoring time. Escalation of ICP management was necessary in more than one-third of patients, and $17 \%$ needed propofol and/or barbiturate coma to control ICP. Our results indicate that although ICP elevation may be less prevalent in DAI compared to focal injuries, ${ }^{21}$ increased ICP is plausibly an important contributor to the risk of secondary injury development also in patients with DAI. Recently it has been suggested that patients with TBI who have a depressed level of consciousness and no or minimal findings on the initial CT scan may not require an ICP monitor. ${ }^{35}$ In our cohort, 41 patients (78.8\%) were classified as diffuse injury I or II on the Marshall CT scoring system at admission, and periods of increased ICP were not infrequent in patients with diffuse injury II (10/14 patients with more than 5\% of GMT with ICP > 20 $\mathrm{mm} \mathrm{Hg}$ had diffuse injury II; data not presented), arguing against refraining from ICP monitoring in unconscious patients with suspected or confirmed DAI.

The maximum ICP has been found to be associated with the number of $\mathrm{T} 2 * \mathrm{GRE}$ lesions in patients with DAI. ${ }^{39}$ Previously, our group identified hemorrhagic lesions in central brainstem structures as particularly associated with unfavorable outcome. ${ }^{1}$ Here, hemorrhagic lesions in the SN-T were not associated with increased ICP. In contrast, patients with nonhemorrhagic lesions seen on DWI sequences in this region had a markedly higher proportion of monitoring time with elevated ICP, and such lesions in the SN-T were independently associated with the proportion of increased ICP. Nonhemorrhagic lesions in this region seem to be less frequent than hemorrhagic lesions, and possibly require a greater degree of trauma to appear, ${ }^{1,14,31}$ thus conveying the increased risk of ICP elevations. It is likely that lesions on DWI sequences in the $\mathrm{SN}-\mathrm{T}$, which were found to be associated with increased ICP in this study, also negatively affect outcome, because 

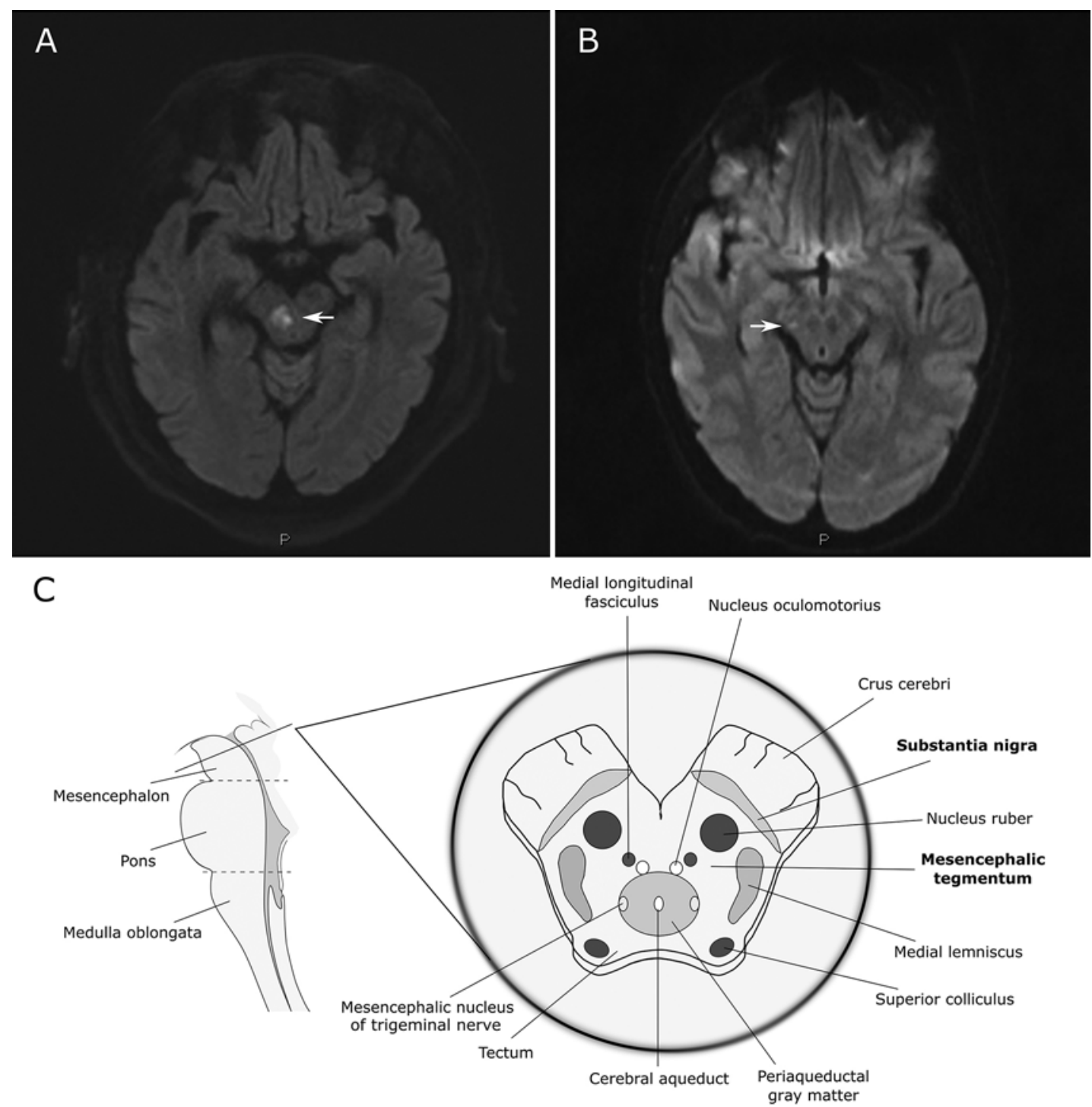

FIG. 2. A: DWI $\left(b=1000 \mathrm{sec} / \mathrm{mm}^{2}\right)$ of a 54 -year-old man who was involved in a motor vehicle accident (MVA). The image displays a centrally located lesion in the mesencephalic tegmentum (arrow). The patient was managed with propofol coma to control ICP. B: DWI $\left(b=1000 \mathrm{sec} / \mathrm{mm}^{2}\right)$ of an 18-year-old man involved in an MVA. The image displays lesions in the right mesencephalic tegmentum (arrow). The patient was managed with CSF drainage to control ICP. C: Anatomical illustration of brainstem and mesencephalic structures. Cross-section of the mesencephalon through the superior colliculi is shown. Central brainstem lesions associated with increased ICP are located in the region of the SN-T (boldface type). As depicted in the figure, this region includes numerous vital structures.

the lesions are located in a region with numerous vital structures (Fig. 2). However, their relative rarity makes their use in prognostication difficult. From this study we cannot verify whether lesions in the SN-T on DWI sequences preceded ICP elevations in all patients, because an MRI session within the first 5 days of monitoring was only performed in 3 of 9 of the patients with these lesions. Future longitudinal studies in which ultra-early MRI is used in patients with DAI can potentially resolve this issue. Still, the findings in this study indicate that visualization of nonhemorrhagic lesions on MRI warrants vigilance for development of increased ICP.

It is unlikely that the development of an ICP crisis in individual patients can with certainty be excluded based on the absence of MRI-confirmed lesions in central brainstem structures. Nonetheless, MR lesion localization in patients with severe TBI with DAI may aid in identifying individuals at risk for the development of increased ICP. Thus, alertness for increased ICP and prophylactic actions in conjunction with NICU interventions can be initiated based on the results from an early MRI scan, in addition to the prognostic value.,17

Age may influence ICP and brain compliance, ${ }^{8,18}$ and lower ICP levels are noted in older patients. ${ }^{7}$ In general, patients with DAI are younger than patients with TBI who have focal injuries. The increased brain volume in the young facilitates the biomechanical strains between the gray and white matter underlying the axonal damage seen 
in DAI, rather than brain movement relative to the skull vault. ${ }^{33}$ Interestingly, age was not significantly associated with ICP in the univariate linear regression analysis (Table 2). However, when adjusted for DWI lesions in the SN-T in the multivariable analysis, age was strongly associated with the proportion of ICP $>20 \mathrm{~mm} \mathrm{Hg}$ during monitoring. This nonsignificant association is plausibly due to the presence of patients with relatively advanced age who had lesions on DWI sequences in the SN-T region, confounding the effect of age on ICP in the univariate analysis. This illustrates the risk of missing associations when statistical models are built based only on results from significance testing in univariate analysis. ${ }^{23,36}$

There are limitations to this study, which need to be considered. The data were gathered during an 8-year period, which may have influenced our results. However, despite the time span of data acquisition, patients were treated using the same standardized ICP- and CPP-guided protocol, collection of physiological data was performed via the same computerized multimodality monitoring system, and all images were acquired with the same 1.5-T MR system, limiting the impact of recall bias.

During the first years of the study, hemorrhagic lesions were mainly studied using a protocol with the T2*GRE sequence only, but over the years, SWI has become the preferred sequence for visualizing hemorrhagic DAI lesions in deep structures. ${ }^{12,26}$ The inconsistency in the MRI sequence used may have caused erroneous results when ICP was evaluated in relation to visualized microhemorrhages. However, the more sensitive SWI sequence was available in the large majority of cases (42/52). In addition, differences in time from injury to the MRI may have resulted in lesions being missed, because nonhemorrhagic lesions in particular change size and signal pattern over time. ${ }^{27}$ In studies of stroke, a gradual increase of the diffusion abnormality during the first 4 days has been observed, and a decrease thereafter. Signals in DWI sequences evolve thus to pseudonormal during the 2 nd week, and ischemic lesions may be missed if the MRI is performed at this time. ${ }^{20}$ There are no detailed longitudinal studies evaluating DAI lesions on DWI during the first weeks, and the temporal pattern may differ between patients with stroke and DAI. Nonetheless, all patients were examined within 6 weeks postinjury and the vast majority (37/52) within the 1st week. Under all circumstances this is the first study to relate minute-by-minute ICP monitoring data to MRI findings in patients with confirmed DAI.

Two different types of images are produced from the DWI sequence: the DW image and the apparent diffusion coefficient (ADC) map. In the DW image, signal intensity depends not only on diffusion, but also on other factors, notably water content, whereas the ADC map only reflects diffusion. In contrast to some previous studies we chose to evaluate the DW images rather than the ADC maps. The rationale for this was that the added contributions from diffusion and water content would be expected to improve the lesion-to-background contrast compared with the ADC map.

\section{Conclusions}

In this study we found that increased ICP is prevalent in approximately one-third of patients with severe TBI who have DAI. Younger age and, in particular, nonhemorrhagic central brainstem lesions in the region corresponding to the SN-T and visualized by the DWI sequence are associated with elevated ICP above the threshold level of $20 \mathrm{~mm} \mathrm{Hg}$. These findings suggest that anatomical lesion localization on MRI may be used to aid prediction of increased ICP in patients with DAI, but that further studies are needed to evaluate the value of an early MRI session.

\section{References}

1. Abu Hamdeh S, Marklund N, Lannsjö M, Howells T, Raininko R, Wikström J, et al: Extended anatomical grading in diffuse axonal injury using MRI: hemorrhagic lesions in the substantia nigra and mesencephalic tegmentum indicate poor long-term outcome. J Neurotrauma 34:341-352, 2017

2. Adams JH, Doyle D, Ford I, Gennarelli TA, Graham DI, McLellan DR: Diffuse axonal injury in head injury: definition, diagnosis and grading. Histopathology 15:49-59, 1989

3. Adams JH, Graham DI, Jennett B: The neuropathology of the vegetative state after an acute brain insult. Brain 123:13271338,2000

4. Andriessen TM, Jacobs B, Vos PE: Clinical characteristics and pathophysiological mechanisms of focal and diffuse traumatic brain injury. J Cell Mol Med 14:2381-2392, 2010

5. Arfanakis K, Haughton VM, Carew JD, Rogers BP, Dempsey RJ, Meyerand ME: Diffusion tensor MR imaging in diffuse axonal injury. AJNR Am J Neuroradiol 23:794-802, 2002

6. Bigler ED: Distinguished Neuropsychologist Award Lecture 1999. The lesion(s) in traumatic brain injury: implications for clinical neuropsychology. Arch Clin Neuropsychol 16:95131, 2001

7. Czosnyka M, Balestreri M, Steiner L, Smielewski P, Hutchinson PJ, Matta B, et al: Age, intracranial pressure, autoregulation, and outcome after brain trauma. J Neurosurg 102:450 454, 2005

8. Depreitere B, Meyfroidt G, Roosen G, Ceuppens J, Grandas FG: Traumatic brain injury in the elderly: a significant phenomenon. Acta Neurochir Suppl 114:289-294, 2012

9. Elf K, Nilsson P, Enblad P: Outcome after traumatic brain injury improved by an organized secondary insult program and standardized neurointensive care. Crit Care Med 30:2129-2134, 2002

10. Fagerholm ED, Hellyer PJ, Scott G, Leech R, Sharp DJ: Disconnection of network hubs and cognitive impairment after traumatic brain injury. Brain 138:1696-1709, 2015

11. Gentry LR: Imaging of closed head injury. Radiology 191:117, 1994

12. Haacke EM, Mittal S, Wu Z, Neelavalli J, Cheng YC: Susceptibility-weighted imaging: technical aspects and clinical applications, part 1. AJNR Am J Neuroradiol 30:19-30, 2009

13. Hayes JP, Bigler ED, Verfaellie M: Traumatic brain injury as a disorder of brain connectivity. J Int Neuropsychol Soc 22:120-137, 2016

14. Hilario A, Ramos A, Millan JM, Salvador E, Gomez PA, Cicuendez M, et al: Severe traumatic head injury: prognostic value of brain stem injuries detected at MRI. AJNR Am J Neuroradiol 33:1925-1931, 2012

15. Howells TP, Jones PA, Piper IR, Souter MJ, Miller JD: Design of a research database for the study of secondary insults following head injury. J Neurotrauma 12:471, 1995 (Abstract)

16. Iverson GL: Outcome from mild traumatic brain injury. Curr Opin Psychiatry 18:301-317, 2005

17. Izzy S, Mazwi NL, Martinez S, Spencer CA, Klein JP, Parikh $\mathrm{G}$, et al: Revisiting grade 3 diffuse axonal injury: not all 
brainstem microbleeds are prognostically equal. Neurocrit Care 27:199-207, 2017

18. Kiening KL, Schoening W, Unterberg AW, Stover JF, Citerio G, Enblad P, et al: Assessment of the relationship between age and continuous intracranial compliance. Acta Neurochir Suppl 95:293-297, 2005

19. Kinnunen KM, Greenwood R, Powell JH, Leech R, Hawkins PC, Bonnelle V, et al: White matter damage and cognitive impairment after traumatic brain injury. Brain 134:449-463, 2011

20. Lansberg MG, Thijs VN, O’Brien MW, Ali JO, de Crespigny AJ, Tong DC, et al: Evolution of apparent diffusion coefficient, diffusion-weighted, and T2-weighted signal intensity of acute stroke. AJNR Am J Neuroradiol 22:637-644, 2001

21. Lee TT, Galarza M, Villanueva PA: Diffuse axonal injury (DAI) is not associated with elevated intracranial pressure (ICP). Acta Neurochir (Wien) 140:41-46, 1998

22. Maas AI, Stocchetti N, Bullock R: Moderate and severe traumatic brain injury in adults. Lancet Neurol 7:728-741, 2008

23. Marill KA: Advanced statistics: linear regression, part II: multiple linear regression. Acad Emerg Med 11:94-102, 2004

24. Marmarou A, Anderson RL, Ward JD, Choi SC, Young HF, Eisenberg HM, et al: Impact of ICP instability and hypotension on outcome in patients with severe head trauma. J Neurosurg 75 Suppl:S59-S66, 1991

25. Marshall LF, Bowers Marshall S, Klauber MR, van Berkum Clark M, Eisenberg HM, Jane JA, et al: A new classification of head injury based on computerized tomography. J Neurosurg 75 Suppl:S14-S20, 1991

26. Mittal S, Wu Z, Neelavalli J, Haacke EM: Susceptibilityweighted imaging: technical aspects and clinical applications, part 2. AJNR Am J Neuroradiol 30:232-252, 2009

27. Moen KG, Skandsen T, Folvik M, Brezova V, Kvistad KA, Rydland J, et al: A longitudinal MRI study of traumatic axonal injury in patients with moderate and severe traumatic brain injury. J Neurol Neurosurg Psychiatry 83:1193-1200, 2012

28. Narayan RK, Kishore PR, Becker DP, Ward JD, Enas GG, Greenberg RP, et al: Intracranial pressure: to monitor or not to monitor? A review of our experience with severe head injury. J Neurosurg 56:650-659, 1982

29. O'Sullivan MG, Statham PF, Jones PA, Miller JD, Dearden NM, Piper IR, et al: Role of intracranial pressure monitoring in severely head-injured patients without signs of intracranial hypertension on initial computerized tomography. J Neurosurg 80:46-50, 1994

30. Saatman KE, Duhaime AC, Bullock R, Maas AI, Valadka A, Manley GT: Classification of traumatic brain injury for targeted therapies. J Neurotrauma 25:719-738, 2008

31. Shibata Y, Matsumura A, Meguro K, Narushima K: Differentiation of mechanism and prognosis of traumatic brain stem lesions detected by magnetic resonance imaging in the acute stage. Clin Neurol Neurosurg 102:124-128, 2000
32. Skoglund K, Enblad P, Hillered L, Marklund N: The neurological wake-up test increases stress hormone levels in patients with severe traumatic brain injury. Crit Care Med 40:216-222, 2012

33. Smith DH, Meaney DF, Shull WH: Diffuse axonal injury in head trauma. J Head Trauma Rehabil 18:307-316, 2003

34. Stein DM, Hu PF, Brenner M, Sheth KN, Liu KH, Xiong W, et al: Brief episodes of intracranial hypertension and cerebral hypoperfusion are associated with poor functional outcome after severe traumatic brain injury. J Trauma 71:364-374, 2011

35. Stocchetti N, Picetti E, Berardino M, Buki A, Chesnut RM, Fountas KN, et al: Clinical applications of intracranial pressure monitoring in traumatic brain injury: report of the Milan consensus conference. Acta Neurochir (Wien) 156:16151622,2014

36. Tu YK, Gunnell D, Gilthorpe MS: Simpson's paradox, Lord's paradox, and suppression effects are the same phenomenonthe reversal paradox. Emerg Themes Epidemiol 5:2, 2008

37. Vik A, Nag T, Fredriksli OA, Skandsen T, Moen KG, Schirmer-Mikalsen K, et al: Relationship of "dose" of intracranial hypertension to outcome in severe traumatic brain injury. J Neurosurg 109:678-684, 2008

38. Wilson JT, Pettigrew LE, Teasdale GM: Structured interviews for the Glasgow Outcome Scale and the extended Glasgow Outcome Scale: guidelines for their use. J Neurotrauma 15:573-585, 1998

39. Yanagawa Y, Sakamoto T, Takasu A, Okada Y: Relationship between maximum intracranial pressure and traumatic lesions detected by $\mathrm{T} 2 *$-weighted imaging in diffuse axonal injury. J Trauma 66:162-165, 2009

\section{Disclosures}

The authors report no conflict of interest concerning the materials or methods used in this study or the findings specified in this paper.

\section{Author Contributions}

Conception and design: Enblad. Acquisition of data: Abu Hamdeh, Howells. Analysis and interpretation of data: Abu Hamdeh, Wikström. Drafting the article: Abu Hamdeh, Enblad. Critically revising the article: Marklund, Lewén, Howells, Raininko, Wikström. Statistical analysis: Abu Hamdeh. Study supervision: Enblad.

\section{Correspondence}

Sami Abu Hamdeh: Uppsala University Hospital, Uppsala, Sweden.sami.abu.hamdeh@neuro.uu.se. 